\title{
IS PUERPERAL INSANITY A DISTINCT CLINICAL FORM?
}

BY W. L. WORCESTER, M. D.,

Assistant Physician, State Lunatic Asylum, Little Rock, Ark.

The classitication of the diseases which manifest thenselves principally in disordered mental action is, and is likely long to remain in an unsatisfactory condition. The reason for this is not far to seek. In order to determine the relations between the groups of phenomena which we call diseases, it is necessary to understand their etiology, their clinical history, and their pathological anatomy. When we know how the cause or causes of a disease bring about the organic ch:nges which, in their turn, produce disorder of function, then, and not till then, we have such a knowledge of the facts as will enable us to judge of their relations to other facts of a more or less similar nature. It is evident that these conditions are far from being fulfilled in regard to most forms of insanity. In a great proportion of cases the causes of the mental derangement are utterly obscure, and in many others so many injurious influences have been at work that it is difficult, if not impossible, to decide which are essential and which unimportant or accessory. The clinical phenomena themselves are of such complexity, and present themselves in such a bewildering variety of combinatious, that it seems almost a hopeless task to reduce them to any sort of order, while as regards pathological anatomy, in spite of all the labor that has been spent upon it, it must be admitted that for the great majority of the affections which come under the care of the alienist, it practically does not exist. Such being the case, it is not surprising that no classification which has yet been devised has met universal, or even general acceptance; that where one, looking at few well-marked cases, sees no difficulty in erecting them into a distinct disease; another, marking the insensible gradations by which they are united with other and very different cases, hesitates to separate them, and not a few are sceptical as to the value of any system, and disposed to harbor the suggestion of a recent writer in Brain, that perhaps "Insanity" alone is a sufficient classification. Still, the human mind will scarcely rest satisfied with such a conclusion, nor is it desirable that it should. Unsystematized knowledge is a constant 
irritation to the scientific mind, and a hindrance to progress. Probably the worst classification that was ever devised is better than none at all.

The etiological classification of mental diseases has never had a very great vogue in this country, and does not seem, on the whole, to be gaining ground at present, but it has enough distinguished advocates to entitle it to a respectful hearing. It is claimed by Skae and his followers that the exciting causes of insanity produce forms of disease that are distinct and characteristic, so that they can be recognized by their clinical course. To what extent is this claim borne out by experience? Is it true that all cases due to masturbation, for instance, or to the puerperal state, or to the climactcric period, present such resemblances between themselves and such differences from those due to all other causes as to entitle them to rank as distinct diseases-distinctive features comparable for instance, to those of typhoid, typhus and malarial fevers? Can the experienced alienist, from the symptoms of the case before him, decide upon the exciting cause, as the dermatologist can say that one case of skin disease is due to the itch-mite, another to the ringworm fungus, and a third to syphilis? Upon the extent to which affirmative answers can be given to these questions, depends, it seems to me, the value of the system.

Among the exciting causes of insanity there is none that is more unquestionable than the puerperal state, and puerperal insanity occupies a prominent place in the systems of Skae and his followers. During my connection with this institution I have had several puerperal cases under my care, and have endeavored to study them with reference to the points indicated above. Probably my conclusions will have more value if accompanied by the facts, on which they are based. The number of cases is not large, but previous experience leads me to think them fairly characteristic.

CASE I.-M. H., aged 26, primipara. Hereditary predisposition denied. Her labor was tedious, and was followed by a severe attack of puerperal fever, in which she was violently delirious, talking incoherently on religious subjects, and at times seeming greatly alarmed without apparent cause. The violence of her excitement subsided as the fever abated, but she continued to be confused, loquacious and silly. She was admitted as a patient March 17, 1888, six months after her confinement. At the time of her admission she was restless, nervous and depressed; walked the floor continually, begging to be taken home. Her condition did 
not change essentially during her stay, although her homesickness varied in intensity from time to time. When not begging to go bome she would repeat some phrase, as, for instance, "fresh butter," by the hour together. During the latter part of her stay she imagined that her busband was in the building, and nothing could convince her to the contrary. She was removed June 1, 1889.

Case II.-A. D., aged 29, mother of four children. Her second confinement, in 1883, was followed by an attack of insanity, from which she recovered in this institution. No mental disturbance followed the birth of the third child, in 1886. The fourth child was born September 13, 1888, and five or six days afterwards she complained of severe pain in the head, became restless, and had hallucinations, the nature of which is not stated. She attempted to kill her husband, manifested suicidal impulses, and was inclined to refuse food. She was admitted to the asylum January 2, 1889. At the time of her admission she was pale, but not greatly emaciated; seemed much depressed; wept, and could with difficulty be induced to eat. In about a week her depression seemed to have passed off to a considerable extent; she was eating well, and seemed rather indifferent to her surroundings; unless prevented, would lie on the floor almost constantly; would say but little. During the following six months she improved to a limited extent. She became less disorderly, but continued to be very indolent, and never could be induced to engage in work of any kind. She would answer when spoken to, but did not engage voluntarily in conversation. There was no incoherence in her talk, and she never expressed any delusions. The only subject in which she ever showed a-lively interest was tobacco, for which she had an inordinate craving. In her husband's absence she seemed to have an aversion for him, and when he visited her would usually refuse, for some time, to speak to him, but would end by talking with him pretty freely and asking to go home. Her physical health soon became fully restored; menstruation was re-established in March, and during the summer she became very fat. After about the first of June her condition remained practically statiouary. She was indolent, indifferent and rather obstinate. She was removed by her husband November 31,1889 , in the hope that the return to the associations of home might arouse her interest and contribute to her recovery, but a letter from him, some months later, stated that she had not improved,

CASE III.-C. B., aged 21, primipara. Hereditary predisposition 
denied. Was confined June 19, 1889, and about two weeks afterwards showed an aversion for her husband, to whom she had previously been very affectionate, and hallucinations of an alarming character, imagining, among other things, that dogs were trying to bite her. She became wildly excited; destroyed clothing, assaulted ber attendants, and attempted suicide by jumping into a well. She was admitted to the asylum July 18, 1889. When received she was quiet, but seemed confused; complained of headache; was in fair flesh, but had a pale, waxy complexion, suggestive of renal disease, of which, however, the urine gave no evidence. That night she broke out the glass of her window, and made a desperate assault on the attendants who came to her room. Until about the first of October there was but iittle change in her mental condition. She was usually quiet and pleasant, but had rather frequent outbursts of apparently causeless violence, in which she would assault any one who happened to be near. On this account she was loosely restrained with wristlets for some weeks, to which she never made any objection. She wandered about the ward, seldom speaking unless addressed, and then answering briefly, but without incoherence. She evidently realized only imperfectly where she was, and mistook the identity of persons; professed to bave no recollection of her confinement. No definite delusions were ever clicited. About the first of October she began to improve rapidly, and by the end of November seemed fully restored. She was discharged as recovered December $22 \mathrm{~d}$.

CASE IV.-F. B., aged 24; primipara. Hereditary predisposition denied. Confined November 24, 1889. The lochial discharge was suppressed prematurely-date not stated-and about two weeks after the birth of her child she was noticed to show an unnatural excitement and elation; was talkative and facetious, restless, and wanted to be constantly running about. At times she attempted violence towards her husband and child, but was never destructive nor filthy. She was received as a patient January 30, 1890. She seemed in good health, although her pulse was rapid (120). She was quite talkative, and often somewhat incoherent, although hor answers to questions were usually relevant. She evidently had vague delusions on religious subjects, but it was impossible to ascertain their precise nature. She made many mysterious gestures. A few days after her admission she announced that her bones were made of glass. In the course of a month she became much more quiet, and very industrious, but was 
very supercilious in her manner; repudiated her name, and wished to be called Wésson, which, it appeared, was the name of a man whom she intended to marry when she obtained her liberty, of which she considered herself unjustly deprived; gave the attendants names of her own devising. At present she acknowledges her name, and is more natural in her manner, but she asserts that her husband was killed before her eyes shortly after she came here, and does not admit that she has been insane at any time. She is anxious to go home to her child.

CaSe V.-E. B., aged 18; primipara. Parents said to have been somewhat intemperate. Confined December 11, 1889, and showed symptoms of insanity two or three days afterward. Had hallucinations; imagined that she saw Christ and the Virgin Mary; afterwards claimed that she was the Virgin Mary, her husband Joseph, and her child Jesus Christ. Was sleepless and restless, loquacious, incoherent, and at times profane and obscene. Admitted to the asylum February 3, 1890. At the time of her admission she was quiet, and evidently much confused; wandered about aimlessly; could be induced to say but little, and was entirely indifferent to cleanliness; requircd much urging to induce her to eat. After a few days she ceased entirely to feed herself, although she wonld eat heartily when food was put into her mouth. In the latter part of March she would only swallow liquids, and soon afterward became decidedly cataleptic; ccased to speak and did not change her position voluntarily. Since about the first of May there has been a slow improvement. At present (June 8,) she eats solid food, but does not feed herself; she changes her position in bed, and gets in and out when told to do so; she can sometimes be induced to say a few words. There has not at any time been evidence of a depressed emotional state. Her expression has been placid, and even when her lethargy was most profound, she would often smile faintly when some jocular remark was addressed to her.

The following three cases may perhaps be conidered to be instances rather of insanity of lactation than puesperal cases, strictly speaking:

Case VI.-N. C., aged 26, mother of four children. The youngest was born in September, 1888. Three months afterward, while suckling the child, as she had done with the previous ones, she became maniacal; laughed immoderately; used profane and obscene language; was violent and destructive. Her excitement subsided to a considerable extent, in the next few months, and she 
became rather indifferent to her surroundings, with occasional violent impulses. She was brought to the asylum October $2,1889$. Her condition has not varied essentially since her admission. She usually sits quietly, without apparently taking much notice of what is going on. Frequently she smiles, and sometimes bursts into langhter, but she scarcely ever speaks, and the little she says throws no light on what is passing in her mind. At times, without provocation or apparent cause, she makes desperate assaults upon patients or attendants, and being a large, powerful woman, she is a decidedly dangerous patient. Her general health has been uniformly good.

CaSe VII.-J. L., aged 21, mother of one child, born in July, 1888. On the ilth of August following, while visiting at the house of a friend, she gave evidence of mental depression; wept; seemed bewildered, and apprehensive. This state of affairs continued; she was unable to fix her mind on anything; became incoherent in speech and silly in conduct, and at times was violent and destructive. She had been deserted by her husband during her pregnancy, but he still remained in the neighborhood, and seeing or hearing of him seemed to aggravate her symptoms. She was received here October 2, 1889. At that time she was thin and pale; there was a moderate degree of exophthalmos, and her pulse was 120 per minute. The thyroid gland was not noticeably enlarged. She seemed confused, timid and apprehensive; talked incoherently, and cridently comprehended scarcely anything of what was said to her. Since then her phrsical health has improved, and she seems less timid than at first, but she is filthy, destructive, noisy at times, and without any apparent comprehension of her surroundings.

Case VIII.-L. L., said to be about twenty years of age, mother of four children, the youngest of whom was born in June, 1889 . About two months later, mental disturbance manifested itself in weeping, incoherent talk, and a disposition to run away from home. When opposed, she became violent, and on one occasion attempted to burn the house. At times she refused food, and this had been the case for several days before her admission to the asylum, May 2, 1890. At first she was very restless, pounding on the door, and calling for various persons. She was inclined to resist everything that was undertaken with her; refused to go to the dining-room, and would not eat when there. After a few days she began to eat very heartily, and her restlessness subsided, but she is inactive, obstinate, suspicious and taciturn. 
In comparing the foregoing cases, it is evident, at the outset, that, notwithstanding their limited number, they present a great variety of symptoms. Excitement and depression, delusions, illusions and hallucinations, suicidal and violent impulses, mental confusion, catalepsy, are all present. It is not clcar, however, that there is any one symptom that is common to them all. Most of the patients seem to have been maniacal at the outset, but Case II would appear to have presented rather the character of agitated melancholia, and it is not disputed that puerperal insanity may set in with melancholic symptoms. Another very general symptom, perhaps present in all the cases in a greater or less degree, is mental confusion. There are no cases among them of simple mania or melancholia. The excitement which they set in seems to have bcen accompanied, in all cases, by delusions or hallucinations, and it is doubtful if any of the patients, at the time of their reception, had a clear comprehension of their surrocindings. Most of them seemed to move in a sort of waking dream. I had, however; at the Michigan Asylum, a patient under my care, who, to the best of my recollection, seemed very clearheaded, and who certainly manifested great ingenuity and judgment of a certain sort in mischief. Obscenity and indecency of conduct, which most writers ou the subject mention as prominent symptoms of puerperal cases, have not been so in my experience, and most of the preliminary histories of the cases treated here are silent on that point.

Assuming that a maniacal onset, with mental confusion, were a universal characteristic of puerperal insanity, instead of being merely its most usual manifestations, would that be sufficient to warrant its separation as a distinct disease? My own observation would lead us to answer this question in the negative, for the reasun that similar cases are not at all uncommon both among nonpuerperal women and men. I have treated a number of patients, both male and female, whose symptoms, so far as I was able to judge, resembled those of the cases I bave detailed in this article quite as much as they resemble each other, and which, apart from etiological considerations, had as good claims to be classed with them as they to be classed together:- I have not been able to discover anything, in the symptoms, whether considered separately or collectively, that would enable me to say, with confidence, in the absence of a history of the case or of physical evidences of recent confinement, that a given patient is a case of puerperal insanity. 